\title{
Protecting the malaria drug arsenal: halting the rise and spread of amodiaquine resistance by monitoring the PfCRT SVMNT type
}

\author{
Juliana M Sa ${ }^{1 *}$, Olivia Twu
}

\begin{abstract}
The loss of chloroquine due to selection and spread of drug resistant Plasmodium falciparum parasites has greatly impacted malaria control, especially in highly endemic areas of Africa. Since chloroquine removal a decade ago, the guidelines to treat falciparum malaria suggest combination therapies, preferentially with an artemisinin derivative. One of the recommended partner drugs is amodiaquine, a pro-drug that relies on its active metabolite monodesethylamodiaquine, and is still effective in areas of Africa, but not in regions of South America. Genetic studies on $P$. falciparum parasites have shown that different pfcrt mutant haplotypes are linked to distinct levels of chloroquine and amodiaquine responses. The pfcrt haplotype SVMNT (termed after the amino acids from codon positions 72-76) is stably present in several areas where amodiaquine was introduced and widely used. Parasites with this haplotype are highly resistant to monodesethylamodiaquine and also resistant to chloroquine. The presence of this haplotype in Africa was found for the first time in 2004 in Tanzania and a role for amodiaquine in the selection of this haplotype was suggested. This commentary discusses the finding of a second site in Africa with high incidence of this haplotype. The $>50 \%$ SVMNT haplotype prevalence in Angola represents a threat to the rise and spread of amodiaquine resistance. It is paramount to monitor pfcrt haplotypes in every country currently using amodiaquine and to re-evaluate current combination therapies in areas where SVMNT type parasites are prevalent.
\end{abstract}

\section{Background}

The article "Plasmodium falciparum isolates from Angola show the StctVMNT haplotype in the pfcrt gene" by Gama BE et al [1] provides results that are more worrisome than surprising. This paper, along with a report from Tanzania [2] and a genetic study between two parasites from Africa and South America [3], highlights an urgent need to examine and update treatment guidelines that use combination therapies with 4-aminoquinolines.

Gama et al examined the prevalence of different haplotypes of the Plasmodium falciparum chloroquine (CQ) resistance transporter gene $p f c r t$, and the multiple drug resistance transporter $p f m d r 1$, from patients in Angola with uncomplicated malaria in 2007. At that time the patients were treated with one of the two artemisinin

\footnotetext{
* Correspondence: jsa@niaid.nih.gov

'Laboratory of Malaria and Vector Research, National Institute of Allergy and Infectious Diseases, National Institutes of Health, 12735 Twinbrook Parkway, Room 3E-10C, Rockville, MD, 20852, USA

Full list of author information is available at the end of the article
}

combination therapies, artemether + lumefantrine or artesunate + amodiaquine (AQ), in accordance with the country's anti-malarial guidelines.

The article reports on the "unexpected" prevalence (> 50\%) of a CQ-resistant pfcrt haplotype often found in other countries including Brazil, India, Papua New Guinea, and the Philippines (termed SVMNT, based on codon positions 72-76, Figure 1). Since the characterization of $p f c r t$ as the main genetic determinant of $\mathrm{CQ}$ resistance [4] and the removal of CQ from WHO antimalarial guidelines in 2000, this is the second report of this haplotype in Africa. While Gama et al propose that the commercial relationship between Brazil and Angola allows for the import of the SVMNT haplotype through travellers, the report in 2006 by Alifrangis et al suggested a role of AQ in the selection of the SVMNT haplotype in Tanzania [2]. Interestingly, two other reports from the same countries show contrasting results regarding the $p f c r t$ haplotype on those areas. The first, in Uige, Angola, shows that in 2004 no SVMNT type parasites were detected [5]. The second is a five-year 


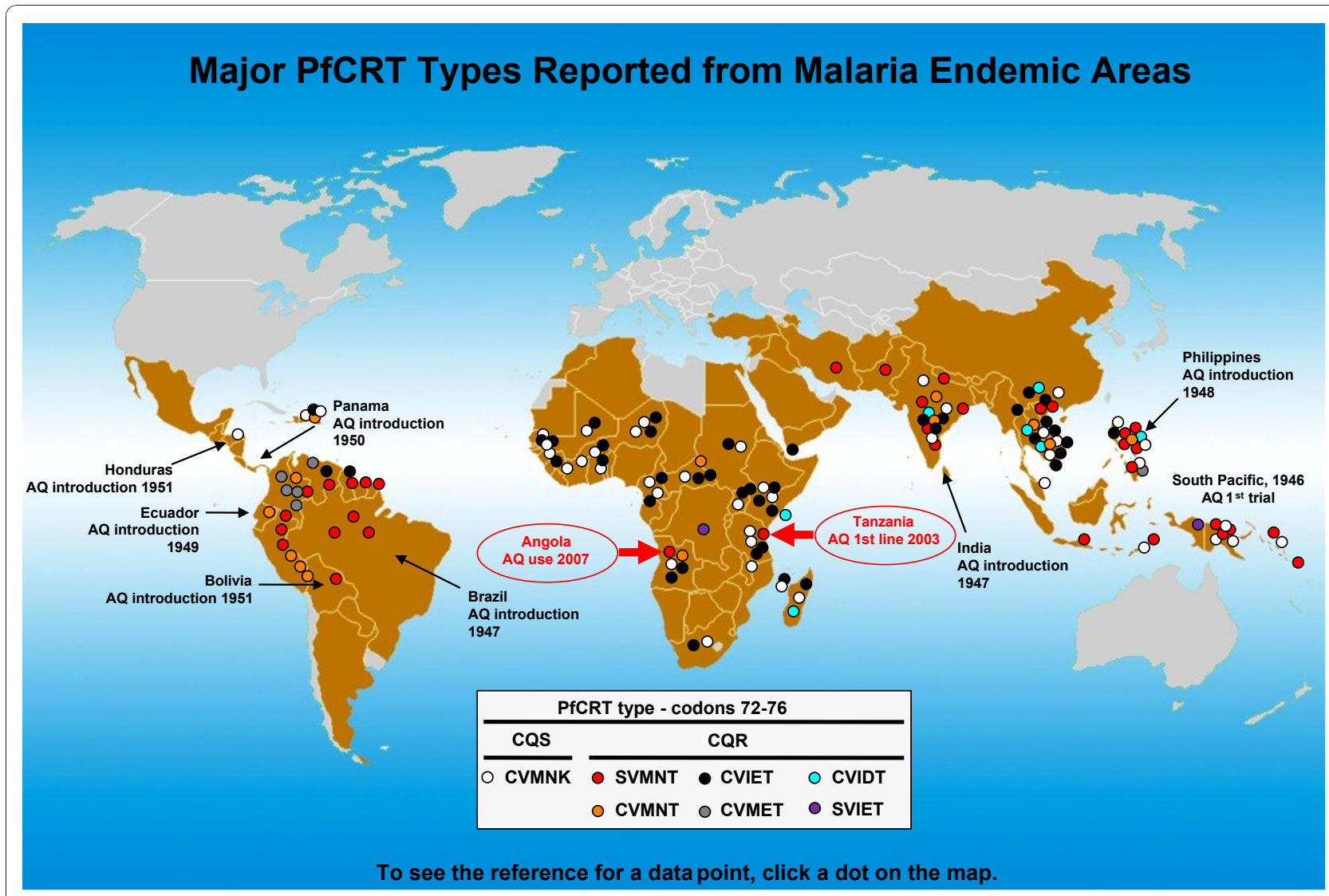

Figure 1 Current worldwide distribution of PfCRT types (codons 72-76, based on the report of more than a single parasite isolate) Regions with previous history of AQ use coincide with areas where the SVMNT haplotype is prevalent. Figure adapted and updated from Sa et al [3].

follow up from Tanzania, in which no SVMNT haplotype was found in 2006 and 2007 after removal of AQ [6]. It is not clear whether differential patterns of parasite transmission levels in distinct geographic locations or drug policy changes may account for this "patchy" distribution of SVMNT type parasites. It is also important to note that after the spread of CQ resistance in Brazil and attempts to re-introduce AQ in the late $1980 \mathrm{~s}$ that country showed the highest level of AQ resistance reported at the time [7]. The appearance and spread of the SVMNT haplotype in Africa, where AQ has been widely used in the past decade in combination therapies should be more expected than surprising.

\section{Discussion}

The analysis of the in vitro responses to $\mathrm{CQ}, \mathrm{AQ}$, and its active metabolite monodesethylamodiaquine (MDAQ) from the $P$. falciparum genetic cross 7G8xGB4, between a CQ-resistant clone from South America carrying the SVMNT pfcrt haplotype and an African clone carrying the CVIET haplotype, showed that these haplotypes are linked to distinct AQ/MDAQ and CQ responses [3]. Parasites with the SVMNT haplotype are highly resistant to MDAQ, but only moderately resistant to $\mathrm{CQ}$, whereas clones with the CVIET haplotype are moderately resistant to MDAQ and highly resistant to $C Q$. These data, coupled with observations on the historical use of $\mathrm{AQ}$ with early trials in India, Brazil, the Philippines, Laos, Ecuador, Bolivia, Honduras, and areas of South Pacific (mostly matching the geographic distribution of the SVMNT haplotype, Figure 1), suggest that AQ had an early and prominent role in the selection of drug resistant SVMNT type parasites. Furthermore, data on the Tanzania genotypes of $P$. falciparum infected samples collected in 2003 and 2004, revealed SVMNT haplotype prevalence of 0\% and $19 \%$, after the increased use of AQ indicating a strong and quick evolutionary force. This idea is also supported by another recent report from Afghanistan, where the prevalence of $P$. falciparum SVMNT type has been associated with AQ resistance [8]. The mechanism by which different $p f c r t$ haplotypes interact with $\mathrm{AQ}$, $\mathrm{MDAQ}$, and CQ is yet to be determined, but it may rely on their specific physicochemical characteristics such as amino acid side-chain volume, charge, and hydrophobicity [9]. 
A greater fitness cost may be associated with parasites carrying the CVIET rather than the SVMNT pfcrt haplotype. While regions in Africa and China where CVIET was the prevalent, if not exclusive haplotype, have been repopulated by CQ-sensitive parasites with the CVMNK haplotype after CQ removal [10-13] regions of South America have remained saturated by the SVMNT haplotype decades after CQ and AQ removal. A reduced fitness cost of the SVMNT haplotype suggests that once this haplotype is present, and CQ and AQ are removed, repopulation of sensitive strains may be very slow to occur.

It is essential to reiterate to the scientific community and government agencies the possibility of this hypothesis: AQ use results in the rapid evolution of 4-aminoquinoline resistant $P$. falciparum parasites of the $p f c r t$ haplotype SVMNT, which easily adapt with relatively little fitness cost. The monitoring of pfcrt codon positions 72-76 from $P$. falciparum infected patients in all countries using AQ in their treatment guidelines, regardless of the combination drug is crucial. An estimation of the current distribution of parasites with this haplotype and the consideration of complete removal of AQ from areas of SVMNT prevalence is important because of the resistance levels of SVMNT parasites and the likelihood that they will be as fit as the drug-resistant parasites from South America, where the treatment options of $\mathrm{AQ}$ as well as CQ have long been lost.

\section{Conclusions}

The continued use of AQ in combination therapies is dangerous in regions where resistant SVMNT parasites occur and threatens the selection of parasites resistant to the partner drug. All efforts should be made to monitor and to halt the selection of SVMNT parasites in Africa and develop new partners in effective combination therapies that will protect the anti-malarial arsenal.

\footnotetext{
Abbreviations

Pfcrt: P. falciparum chloroquine resistance transporter gene; CQ: chloroquine; AQ: amodiaquine; MDAQ: monodesethylamodiaquine.
}

\section{Acknowledgements}

We thank Cameron Bess, Erika Phelps, Sarah Kaslow, Rick Fairhurst, and Thomas E. Wellems for encouraging and reviewing this commentary. The Intramural Research Program of the National Institutes of Health, National Institute of Allergy and Infectious Diseases supported this research.

\footnotetext{
Author details

${ }^{1}$ Laboratory of Malaria and Vector Research, National Institute of Allergy and Infectious Diseases, National Institutes of Health, 12735 Twinbrook Parkway, Room 3E-10C, Rockville, MD, 20852, USA. ²Dept of Microbiology, Immunology and Molecular Genetics, University of California Los Angeles, 1602 MSB, 609 Charles E. Young Dr. East, Los Angeles, CA, 90095, USA.
}

\section{Competing interests}

The authors declare that they have no competing interests.

Received: 15 November 2010 Accepted: 23 December 2010 Published: 23 December 2010

\section{References}

1. Gama BE, Pereira de Carvalho GA, Lutucuta Kosi FJ, Almeida de Oliveira NK, Fortes F, Rosenthal PJ, Daniel Ribeiro CT, Ferreira da Cruz MD: Plasmodium falciparum isolates from Angola show the StctVMNT haplotype in the pfcrt gene. Malar J 2010, 9:174

2. Alifrangis $M$, Dalgaard MB, Lusingu JP, Vestergaard LS, Staalsoe $T$, Jensen AT, Enevold A, Ronn AM, Khalil IF, Warhurst DC, Lemnge MM, Theander TG, Bygbjerg IC: Occurrence of the Southeast Asian/South American SVMNT haplotype of the chloroquine-resistance transporter gene in Plasmodium falciparum in Tanzania. J Infect Dis 2006, 193:1738-1741

3. Sa JM, Twu O, Hayton K, Reyes S, Fay MP, Ringwald P, Wellems TE: Geographic patterns of Plasmodium falciparum drug resistance distinguished by differential responses to amodiaquine and chloroquine. Proc Natl Acad Sci USA 2009, 106:18883-18889.

4. Fidock DA, Nomura T, Talley AK, Cooper RA, Dzekunov SM, Ferdig MT, Ursos LM, Sidhu AB, Naude B, Deitsch KW, Su XZ, Wootton JC, Roepe PD, Wellems TE: Mutations in the $P$. falciparum digestive vacuole transmembrane protein PfCRT and evidence for their role in chloroquine resistance. Mol Cell 2000, 6:861-871.

5. Menegon M, Pearce RJ, Inojosa WO, Pisani V, Abel PM, Matondo A, Bisoffi Z, Majori G, Ord R, Warhurst DC, Roper C, Severini C: Monitoring for multidrug-resistant Plasmodium falciparum isolates and analysis of pyrimethamine resistance evolution in Uige province, Angola. Trop Med Int Health 2009, 14:1251-1257.

6. Alifrangis $M$, Lusingu JP, Mmbando B, Dalgaard MB, Vestergaard LS, Ishengoma D, Khalil IF, Theander TG, Lemnge MM, Bygbjerg IC: Five-year surveillance of molecular markers of Plasmodium falciparum antimalarial drug resistance in Korogwe District, Tanzania: accumulation of the $581 \mathrm{G}$ mutation in the $P$. falciparum dihydropteroate synthase gene. Am J Trop Med Hyg 2009, 80:523-527.

7. Kremsner PG, Zotter GM, Grainger W, Feldmeier H: Amodiaquine-resistant malaria in Brazil. Lancet 1987, 2:684.

8. Beshir K, Sutherland CJ, Merinopoulos I, Durrani N, Leslie T, Rowland M, Hallett RL: Amodiaquine resistance in Plasmodium falciparum malaria is associated with the pfcrt 72-76 SVMNT allele in Afghanistan. Antimicrob Agents Chemother 2010.

9. Warhurst DC: Polymorphism in the Plasmodium falciparum chloroquineresistance transporter protein links verapamil enhancement of chloroquine sensitivity with the clinical efficacy of amodiaquine. Malar J 2003, 2:31

10. Kublin JG, Cortese JF, Njunju EM, Mukadam RA, Wirima JJ, Kazembe PN, Djimde AA, Kouriba B, Taylor TE, Plowe CV: Reemergence of chloroquinesensitive Plasmodium falciparum malaria after cessation of chloroquine use in Malawi. J Infect Dis 2003, 187:1870-1875.

11. Wang X, Mu J, Li G, Chen P, Guo X, Fu L, Chen L, Su X, Wellems TE: Decreased prevalence of the Plasmodium falciparum chloroquine resistance transporter 76T marker associated with cessation of chloroquine use against $P$. falciparum malaria in Hainan, People's Republic of China. Am J Trop Med Hyg 2005, 72:410-414.

12. Laufer MK, Thesing PC, Eddington ND, Masonga R, Dzinjalamala FK, Takala SL, Taylor TE, Plowe CV: Return of chloroquine antimalarial efficacy in Malawi. N Engl J Med 2006, 355:1959-1966.

13. Mwai L, Ochong E, Abdirahman A, Kiara SM, Ward S, Kokwaro G, Sasi P, Marsh K, Borrmann S, Mackinnon M, Nzila A: Chloroquine resistance before and after its withdrawal in Kenya. Malar J 2009, 8:106.

doi:10.1186/1475-2875-9-374

Cite this article as: Sa and Twu: Protecting the malaria drug arsenal: halting the rise and spread of amodiaquine resistance by monitoring the PfCRT SVMNT type. Malaria Journal 2010 9:374. 